\title{
Charge analysis on lightning discharges to the ground in Chinese inland plateau (close to Tibet)
}

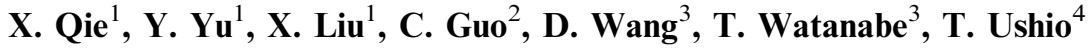 \\ ${ }^{1}$ Cold and Arid Regions Environmental and Engineering Research Institute, Chinese Academy of Sciences, Lanzhou, \\ Gansu 730000, P.R. China \\ ${ }^{2}$ Shanghai Meteorological Institute, P.R. China \\ ${ }^{3}$ Gifu University, Gifu, Japan \\ ${ }^{4}$ Osaka University, Osaka, Japan
}

Received: 8 November 1999 / Revised: 14 April 2000 / Accepted: 17 May 2000

\begin{abstract}
Since the summer of 1996, scientists from China and Japan have conducted a joint observation of natural cloud-to-ground lightning discharges in the Zhongchuan area that is located close to QinghaiXizang (Tibet) Plateau, China. It has been found that the long-duration of intracloud discharge processes, just before the first return stroke, lasted more than $120 \mathrm{~ms}$ for $85 \%$ of cloud-to-ground flashes in this area, with a mean duration of $189.7 \mathrm{~ms}$ and a maximum of $300 \mathrm{~ms}$. We present the results of charge sources neutralized by four ground flashes and two intracloud discharge processes, just before the first return stroke, by using the data from a 5-site slow antenna network synchronized by GPS with $1 \mu$ s time resolution. The result shows that the altitudes of the neutralized negative charge for three negative ground flashes were between 2.7 to $5.4 \mathrm{~km}$ above the ground, while that of neutralized positive charges for one positive ground flash and one continuing current process were at about $2.0 \mathrm{~km}$ above the ground. The comparison with radar echo showed that the negative discharges initiated in the region greater than $20 \mathrm{dBZ}$ or near the edge of the region with intense echoes greater than $40 \mathrm{dBZ}$, while positive discharge initiated in the weak echo region.
\end{abstract}

Key words: Meterology and atmospheric dynamics (atmospheric electricity; convective processes; lightning)

\section{Introduction}

The unusual characteristics of Chinese inland plateau, thunderstorms have been widely noticed in China since the 1980s (Wang et al., 1987; Liu et al., 1987, 1989).

Correspondence to: $\mathrm{X}$. Qie

e-mail: qiex@ns.lzb.ac.cn
This result was based originally upon observations made with a field mill by noting the change of the field when the thunderstorm was overhead. It was deduced that the charge structure of most storms in Gansu Province, located near the Qinghai-Xizang Plateau of China, was positively tripolar, i.e., an upper positive charge and a main negative charge below the positive. However another positive charge region comparable in amount to the upper positive charge region is widely distributed at the base of thundercloud. In 1989, Liu et al. (1989) found, using the recordings of $E$ and $\Delta E$ measured by field mills, that most of the intracloud discharges took place between the main negative charge region and the lower positive charge region instead of upper positive charge region.

To better understand the charge structure of thunderstorms and discharge features on Chinese Inland Plateau, scientists from China and Japan jointly conducted a multi-station simultaneous observation of natural lightning in the summer of 1996 in Zhongchuan Latitude $36^{\circ} 36^{\prime} \mathrm{N}$, Longitude $103^{\circ} 36^{\prime} \mathrm{E}$, Lanzhou which is also located in the verge of Qinghai-Xizang Plateau. Here we use lightning-caused field changes on the surface to estimate the locations and magnitudes of charges neutralized by lightning discharge.

The multi-station measurement of lightning electric field change is one of the most effective ways to study the charge structure of thunderstorms. Workman et al. (1942) made the first time-resolved simultaneous measurement of electric field change caused by lightning discharge at eight stations in New Mexico. The data were used to calculate the location of the charge center for individual strokes of discharges to the ground and for complete intracloud (IC) discharges. They found that both the negative and positive charges lay within a limited range of ambient cloud temperature between $-5{ }^{\circ} \mathrm{C}$ and $-25{ }^{\circ} \mathrm{C}$, and were distributed horizontally within the storm. Later several other multi-station lightning studies were conducted to investigate the relative locations of charges involved in successive strokes of discharges to the ground (Reynolds and 
Neill, 1985; Ogawa and Brook, 1969; Krehbiel et al., 1979; Brook et al., 1982) or determine charge locations for ground flashes as a whole (Barnard, 1951; Jacobson and Krider, 1976). In Florida, a large-area network of electric field mills and other instruments were used to investigate the electrical structure of Florida thunderstorm (Jacobson and Krider, 1976; Maier and Krider, 1986; Krider, 1989; Koshak and Krider, 1989; Murphy et al., 1996). They found that the point charge $(Q)$ fits cloud-to-ground $(\mathrm{CG})$ flashes and the point-dipole $(p)$ model fits IC discharges in Florida. The $Q$-solutions tend to concentrate where the environmental air temperature are between -10 to $-20^{\circ} \mathrm{C}$, or 6 to $8 \mathrm{~km}$ above sea level (asl). The $p$-vectors tend to be located at both above and below the $Q$-region and point toward the $Q$ region. A similar method was also employed to investigate the initial development of vertical intracloud lightning discharges (Liu and Krehbiel, 1985) and the location of pulses in preliminary breakdown processes (Ushio et al., 1996).

We report results of electric field change measurements for lightning discharges made at five surface stations during a thunderstorm. The measurements were of sufficient accuracy and time resolution to allow the charge sources of individual strokes of ground discharges to be located. At the same time, a radar measurement was made so that the charge calculated could be related to the storm environment. In addition to providing basic data about ground discharges themselves, such data and study have an important bearing on our understanding of the electrical structure of plateau thunderstorms in China.

\section{Experiment}

A map of measurement network is shown in Fig. 1. Five stations covered an area of $10 \times 10 \mathrm{~km}^{2}$ in Zhongchuan, northwest of Lanzhou, at the eastern edge of QinghaiXizang Plateau. The altitude of this area was about $2 \mathrm{~km}$ above sea level. The central station was the A-station known as Shanzidun. There were no high buildings or trees around. The development of storms

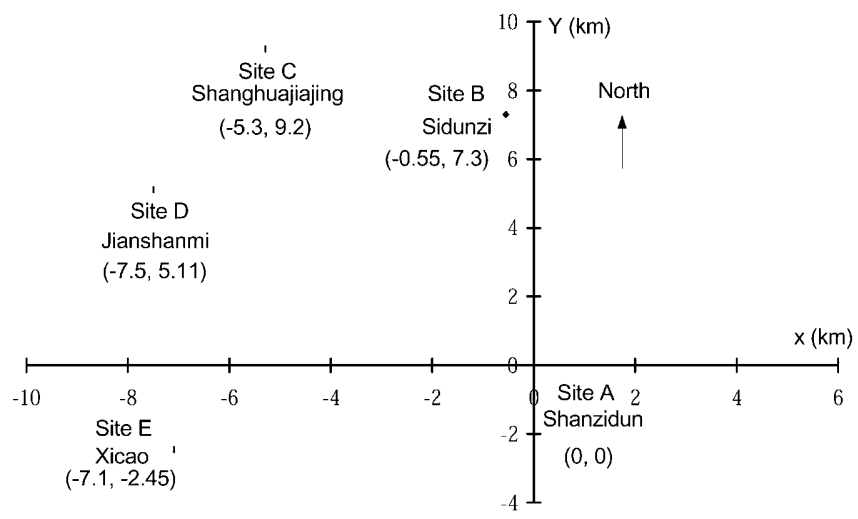

Fig. 1. Map of the electric field change measurement station. The coordinates of the radar station were $(10.9 \mathrm{~km},-58.6 \mathrm{~km})$ over the network was monitored and recorded by a $5-\mathrm{cm}$ wavelength radar, which was located at about $60 \mathrm{~km}$ southeast of A-station, about $2129 \mathrm{~m}$ above sea level. The Cartesian coordinates of the radar station were $(10.9 \mathrm{~km},-58.6 \mathrm{~km})$.

During the 1996 experiment, the electric field and field changes generated by cloud-to-ground lightning discharges were recorded by the 5-station slow antenna system and field mills separately. The data presented were mainly from the slow antenna system with a time constant of about $5 \mathrm{~s}$ and a bandwidth of $0.2 \mathrm{~Hz}$ to $2 \mathrm{MHz}$. The output of slow antenna was digitized at a sampling frequency of $1 \mathrm{MHz}$ and an amplitude resolution of 12 bits. The data were recorded by a PC with a recording length of $1 \mathrm{M}$ words for each lightning discharge. The signals from different stations were synchronized by GPSs with 1 microsecond time resolution. In addition to the slow antenna and field mill sensors, three all-sky video cameras were mounted at station A, station B and station $\mathrm{C}$ to photograph the lightning channel and determine the horizontal location of ground flashes.

\section{Charge model and analysis method}

In this study, we used a point charge model to determine the location in cloud and the magnitude of charge center neutralized by ground lightning flashes, through simultaneous measurements of the electric field change at five stations. For a charge $Q$ brought to earth by ground lightning, the field changes at $i$ th station is given by

$$
\Delta E_{i}=\frac{1}{4 \pi \varepsilon_{0}} \frac{2 Q z}{\left[\left(x-x_{i}\right)^{2}+\left(y-y_{i}\right)^{2}+z^{2}\right]^{3 / 2}}=\frac{1}{4 \pi \varepsilon_{0}} \frac{2 Q z}{R_{i}^{3}}
$$

where the $x, y, z$ are coordinates of point charge $Q ; x_{i}, y_{i}$ are the coordinate of $i$ th station; $R_{i}$ is the distance between $Q$ and the $i$ th station. $\varepsilon_{0}$ is the permittivity of vacuum (which is essentially equal to the permittivity of atmospheric air). All are in mks units. To determine $x, y, z$ and $Q$ of ground lightning discharge, four independent measurements are sufficient in principle. The use of an overdetermined data set serves to improve the accuracy and also make possible to calculate a quantitative error estimation.

Neutralization or rearrangement of charge by intracloud processes which neutralize both positive and negative charges in the cloud, is usually modeled by means of discrete models, utilizing two point charges of equal and opposite charge value. When the spacing between the two charges is not large, the field changes at the ground approaches that of a point dipole, given by

$\Delta E_{i}=\frac{1}{4 \pi \varepsilon_{0}}\left[\frac{2 p_{z}}{R_{i}^{3}}-\frac{6 z}{R_{i}^{5}} \vec{R}_{i} \cdot \vec{p}\right]$

where $\vec{p}=Q \Delta \vec{R}_{i}=p_{x} \vec{i}_{x}+p_{y} \vec{i}_{y}+p_{z} \vec{i}_{z}$ is the dipole moment vector, and $R_{i}$ is the distance between the center of point-dipole $(x, y, z)$ and observer $\left(x_{i}, y_{i}\right)$. The model has 
six unknown parameters. The point-dipole charge model is widely used when the number of observation stations is limited.

If $\vec{p}$ is set in spherical coordinate system, then

$$
\begin{aligned}
\Delta E_{i}=\frac{P}{4 \pi \varepsilon_{0}}[ & \cos \theta\left(\frac{1}{R_{i}^{3}}-\frac{3 z}{R_{i}^{5}}\right) \\
& \left.-\frac{3 z}{D_{i} R_{i}^{4}}(\mathrm{~d} x \sin \varphi+\mathrm{d} y \cos \varphi)\right]
\end{aligned}
$$

where $\theta$ is elevation angle of $\vec{p}$, with the vertically upward direction denoted as $0^{\circ} ; \phi$ is its azimuth with north is denoted as $0^{\circ}$ and it increases clockwise. In this expression the six unknown parameters are $(x, y, z, p, \theta, \phi)$.

The numerical method used here is the nonlinear least square fitting as described by Krehbiel et al. (1979). It consists of performing a nonlinear least square fit of the data to the charge model, deriving a Chi-square estimate of the 'goodness of fit'. The function to be determined, for the point charge model, is the reduced Chi-square

$\chi_{v}^{2}=\frac{1}{v} \sum_{i=1}^{n} \frac{\left[\Delta E_{m i}-\Delta E_{i}(x, y, z, Q)\right]^{2}}{\sigma_{i}^{2}}$

where $\Delta E_{m i}$ is the electric field change measured at the $i$ th station, and $\Delta E_{i}(x, y, z)$ is the fitted value of the field change as calculated from the model, $\sigma_{i}^{2}$ is the estimated variance of the measurement in $\Delta E_{m i}$ due to experimental errors, $\sigma_{i}$ was estimated at $10 \%$ in the calculations, $v$ is the number of degrees of freedom, $n-m$, where $n$ is the number of independent station points (here 5) and $m$ is the number of unknowns. The best result is defined as that which minimizes the deviation between the observed and fitted values, as measured by the Chisquare $\left(\chi^{2}\right)$ statistic of goodness of fit. The uncertainty of the results can be derived from the error matrix, which is the inverse of the curvature matrix of $\chi^{2}$ hypersurface in $x, y, z$, and $Q$ space.

\section{Data and results}

In this section we present results of a detailed analysis of electric field measurements for cloud-to-ground lightning flashes. The flashes were produced by a storm on August 12, 1996, that developed from the west of D station and then moved southeast. The first cloud-toground flash was observed at 16:18:36 (Beijing Time) at three stations (C, D and E stations). 29 cloud-to-ground lightning flashes were produced by the storm during $1 \mathrm{~h}$ and 17 min following the first flash including 9 positive and 20 negative flashes. To be analyzed here are flash 11, flash 12, flash 13 and flash 22 including three negative (lower negative charge to the ground) and one positive (lower positive charge to the ground) discharges. These flashes were selected for analysis because each produced large but unsaturated amplitude recordings at all the five measurement stations.

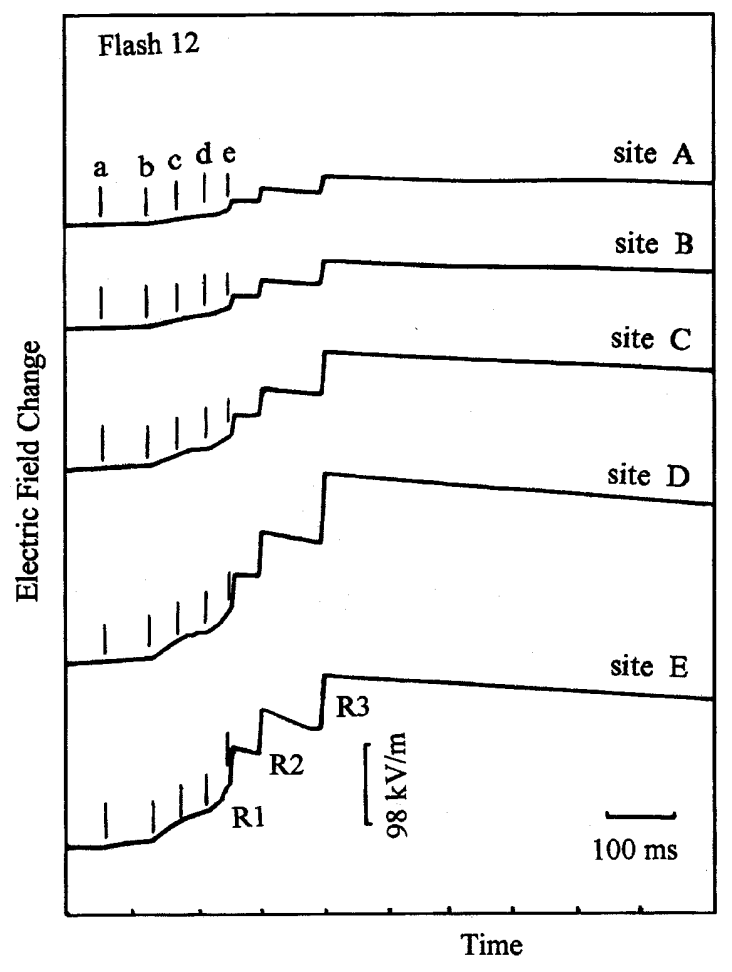

Fig. 2. Electric field change versus time for flash 12, 16:42:20 (Beijing Time). Upward deflection indicate a decrease of negative charge overhead. Line segments before first return stroke denote the different part of the preliminary breakdown process

Electric field measurements obtained for Flash 12 occurred at 16:42:20, are shown in Fig. 2. The upward or positive change shows that it was a negative ground flash. The magnitude of the total field change ranged from $68.4 \mathrm{~V} / \mathrm{m}$ at A station to $230.7 \mathrm{~V} / \mathrm{m}$ at $\mathrm{D}$ station. This flash occurred $20 \mathrm{~km}$ west and $3 \mathrm{~km}$ north of the A-station according to the all-sky video camera at three stations.

The flash consisted of three individual strokes to the ground, and each stroke was characterized by a leader and return stroke change, the latter of which appears as a positive step labeled R1, R2 and R3. The positive electric field change before the first return stroke (R1) lasted about $200 \mathrm{~ms}$. Generally, a stepped leader progresses to the ground at a speed of $10^{5} \mathrm{~m} / \mathrm{s}$ and leaves a weak ionized channel behind for first return stroke. Assuming that the stepped leader travels about 3 to $6 \mathrm{~km}$ distance from cloud to the ground, the time of progression is about 30 to $60 \mathrm{~ms}$. This indicates that the electric field changes prior to the first return stroke here were not completely produced by the stepped leader, but the initial part was produced by a long-duration intracloud discharge process. Because of this event, it was hard to distinguish the start of the stepped leader from the preceding intracloud activity. Subsequent strokes of the flash were initiated by dart-type leaders which are typically less than $3 \mathrm{~ms}$ in duration. Only the change caused by return stroke was considered when the first return stroke was analyzed, and the change produced by stepped leader was neglected, while the electric field change produced both by return stroke and 
dart leader was considered together for subsequent return strokes.

The long-duration intracloud discharge process before the first return stroke was a very common event over the Chinese Inland Plateau. Twenty one out of 29 cloud-to-ground flashes in this thunderstorm were preceded by a long-duration intracloud discharge process which usually lasted for $120 \mathrm{~ms}-300 \mathrm{~ms}$. The electric field change produced by the intracloud discharge process was usually rising and the discharge was well underway when first return stroke occurred.

To study the characteristics of intracloud discharge process just before the first return stroke, the electric field changes were divided into four stages labeled ' $a$ ' to 'e' as shown in Fig. 2. They were fitted by using a pointdipole charge model.

Figure 3 shows the recorded electric field changes for flash 11 occurred at 16:39:41. The flash produced two strokes to the ground labeled R1 and R2. A complete waveform of the intracloud discharge process just before R1 was observed at E-station, and it lasted about $200 \mathrm{~ms}$. Other stations did not record the complete waveform of intracloud discharge. The intracloud discharge process of this flash will not be discussed here.

Figure 4 shows the electric field change at five stations produced by the negative cloud-to-ground flash 22 , and occurred at 17:24:22. This flash produced only one stroke to the ground which is labeled $\mathrm{R}$. The weak step change followed return stroke $\mathrm{R}$ characterized by slow change corresponding to ' $\mathrm{K}$ ' events in the cloud. Just before the return stroke, positive field changes were observed at four stations including station A, B, C, and $\mathrm{D}$, while negative field changes were observed at station E. The duration of intracloud discharge process just

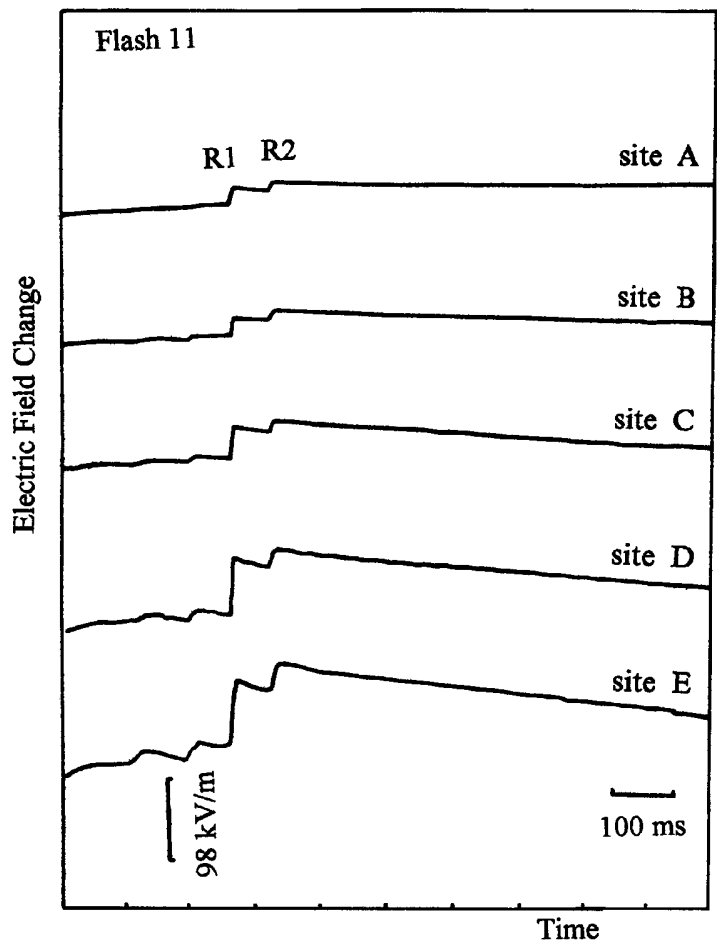

Fig. 3. Electric field change versus time for flash 11, 16:39:41

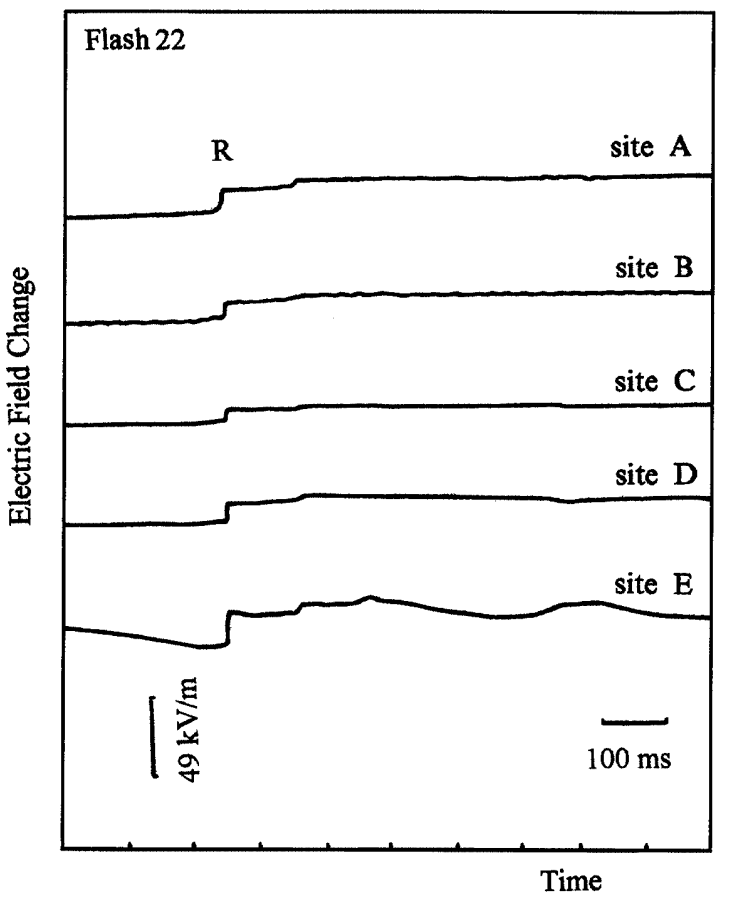

Fig. 4. Electric field change versus time for flash 22, 17:24:22

before R1 was about $240 \mathrm{~ms}$. The opposite polarity of the intracloud discharge was caused by different distances from the discharge sources to the stations.

Figure 5 shows a positive cloud-to-ground flash 13, which occurred at 16:44:44. The waveform could be divided into three different parts: $\mathrm{a}-\mathrm{e}$, $\mathrm{e}-\mathrm{f}$ and $\mathrm{f}-\mathrm{g}$ as shown in Fig. 5. The electric field change during e-f interval was produced by a return stroke, and that of $\mathrm{f}-\mathrm{g}$

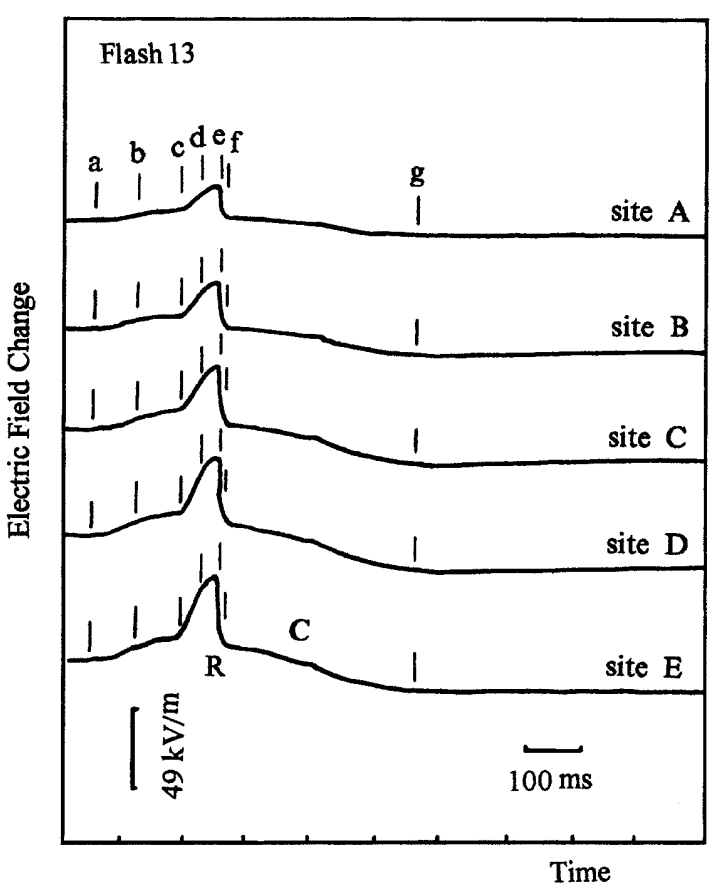

Fig. 5. Electric field change versus time for flash 13, 16:44:44 
interval, which is $300 \mathrm{~ms}$ in duration, was produced by a long continuing current event. The first part $(\mathrm{a}-\mathrm{b}-\mathrm{c}-\mathrm{d}-\mathrm{e})$ lasted for about $210 \mathrm{~ms}$, which corresponded to a longduration intracloud discharge.

\section{Lightning charge locations and magnitudes}

The structure of the ground stroke charges for each of the flashes studied is summarized in Figure 6. The small circles denoted the size of spherical volumes which would have contained the individual stroke charges at the uniform density of $20 \mathrm{C} / \mathrm{km}^{3}$. The charge values, goodness of fit, and other relative information are summarized in Table 1. The magnitude of charge lowered by discrete negative ground strokes ranged from a maximum of $5.44 \mathrm{C}$ to a minimum of $2.74 \mathrm{C}$, and was much less than that lowered by positive stroke. First strokes tended to be more energetic than subsequent ones, although the difference was not large. The charge neutralized by individual negative ground strokes was of small magnitudes. The total charge lowered to the ground by one negative flash was no more than 11.0 C. The magnitude of charge lowered by discrete negative ground strokes is in good agreement with that reported by Krehbiel et al. (1979), however, the total charge lowered by one flash is about 4 times less than that reported by Krehbiel et al. (1979). The uncertainties given for the various charge center results in Table 1 are too small in view of the relatively large distance of the flashes from the measurement network. This may result from the fact that the Chi-square values are small due to having only one redundant station.

The centers of the negative charge neutralized by discrete strokes were located between $2.74 \mathrm{~km}$ to $5.41 \mathrm{~km}$ above the ground. The horizontal location of flash 12 was in good agreement with that determined by all-sky video camera at three stations. The charge centers for the ground strokes of flashes 12 and 11 developed horizontally northeast or southwest in the
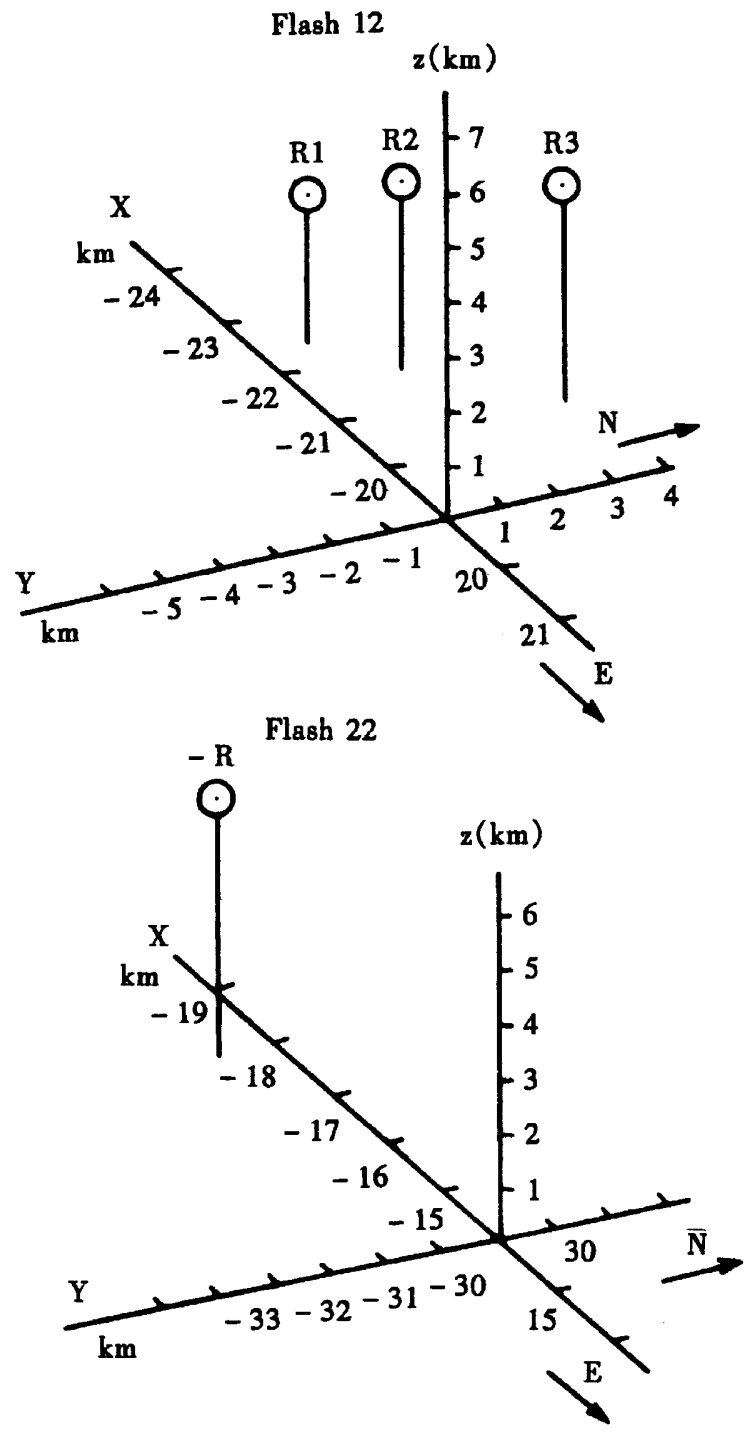

Flash 11

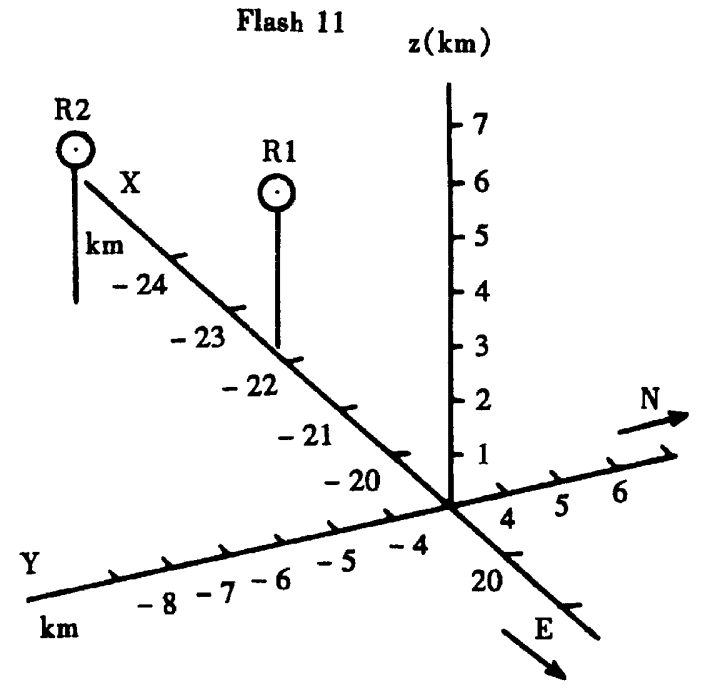

Flash 13

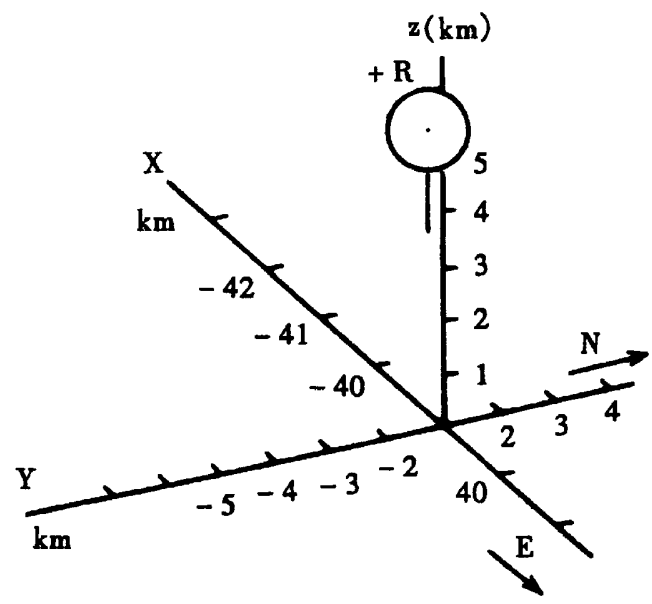

Fig. 6. The structure of the ground stroke charges for each of the flashes. The small circles denote the size of spherical volumes which would have contained the individual stroke charges at the uniform density of $20 \mathrm{C} / \mathrm{km}^{3}$ 
Table 1. Location and magnitude of charges neutralized by return strokes and continuing current

\begin{tabular}{|c|c|c|c|c|c|c|}
\hline Flash & $\begin{array}{l}\text { Stroke } \\
\text { number }\end{array}$ & $x \quad(\mathrm{~km})$ & $y(\mathrm{~km})$ & $z(\mathrm{~km})$ & $Q(\mathrm{C})$ & $\chi^{2}$ \\
\hline \multicolumn{7}{|c|}{ Negative flash } \\
\hline \multirow[t]{3}{*}{12} & $\mathrm{R} 1$ & $-23.39 \pm 0.01$ & $0.62 \pm 0.07$ & $2.74 \pm 0.01$ & $3.83 \pm 0.01$ & 0.05 \\
\hline & $\mathrm{R} 2$ & $-21.72 \pm 0.01$ & $2.02 \pm 0.02$ & $3.51 \pm 0.01$ & $3.11 \pm 0.01$ & 0.70 \\
\hline & R3 & $-20.63 \pm 0.05$ & $4.30 \pm 0.18$ & $3.94 \pm 0.04$ & $3.44 \pm 0.02$ & 0.55 \\
\hline \multicolumn{4}{|c|}{ Total charge (C) } & & 10.4 & \\
\hline \multirow[t]{2}{*}{11} & $\mathrm{R} 1$ & $-22.25 \pm 0.01$ & $0.01 \pm 0.01$ & $2.96 \pm 0.001$ & $5.44 \pm 0.0001$ & 0.62 \\
\hline & $\mathrm{R} 2$ & $-23.64 \pm 0.001$ & $-5.27 \pm 0.02$ & $2.84 \pm 0.003$ & $3.15 \pm 0.001$ & 1.34 \\
\hline \multicolumn{2}{|c|}{ Total charge (C) } & & & & 8.59 & \\
\hline 22 & $-\mathrm{R}$ & $-17.70 \pm 0.03$ & $-30.61 \pm 0.012$ & $5.41 \pm 0.005$ & $2.74 \pm 0.001$ & 4.88 \\
\hline \multicolumn{7}{|c|}{ Positive flash } \\
\hline \multirow[t]{2}{*}{13} & $+\mathrm{R}$ & $-41.91 \pm 0.01$ & $4.32 \pm 0.09$ & $1.73 \pm 0.01$ & $41.67 \pm 0.02$ & 0.36 \\
\hline & $+\mathrm{c}$ & $-32.84 \pm 0.01$ & $8.86 \pm 0.04$ & $1.60 \pm 0.01$ & $26.46 \pm 0.02$ & 1.59 \\
\hline \multicolumn{2}{|c|}{ Total charge (C) } & & & & 68.13 & \\
\hline
\end{tabular}

cloud, which was $4.6 \mathrm{~km}$ for flash 12 and $5.5 \mathrm{~km}$ for flash 11, respectively. This indicated that the lightning channel was mainly extended horizontally.

The center of charge neutralized by flash 13 was $1.73 \mathrm{~km}$ above the ground. The ' $+\mathrm{c}$ ' in Table 1 is associated with a long post-stroke continuing current event. Since the continuing current flowed to the ground following the return stroke channel, it can also be fitted with a point charge model. The altitude of the charge neutralized by continuing current was $1.60 \mathrm{~km}$ above the ground which was close to that of the return stroke. The electric charge lowered to the ground by positive discharge is much greater than that lowered by negative discharge. The charge lowered to the ground by the positive flash was $68.13 \mathrm{C}$ including the return stroke and continuing current, which was seven times greater than that released by negative flashes. The electric charge transported by continuing current in $300 \mathrm{~ms}$ was $26.46 \mathrm{C}$, corresponding to an average current of $88.2 \mathrm{~A}$. This result is smaller than that obtained by Brook et al. (1982) in Japanese winter thunderstorms, whose result for positive ground flashes was $200 \mathrm{~A}$ to $40 \mathrm{kA}$. This disagreement may be attributed to the difference in center locations of the neutralized charge. Positive discharge occurred in Japanese winter thunderstorms initiated in the upper positive charge region, while that initiated in a lower positive region for Chinese inland plateau thunderstorms.
In addition to the ground stroke results, the field changes caused by intracloud discharge process just before R1 have been analyzed to determine the dipolar rearrangement of charge that accompanied this process. The field changes were divided into several intervals, and were analyzed by using the point dipole charge model as a series of field changes, each beginning at the starting point of intracloud discharge process. Since five stations were not enough to determine the six unknown parameters in the point dipole model, we calculated other five unknowns for certain $\theta$, say $10^{\circ}$, then repeated the calculation by increasing $10^{\circ}$ until $\theta=90^{\circ}$. In this way, the freedom is 0 , and as a result the uncertainty increased. After nine repeat calculations, we chose a group of result with the best goodness of fit and the least error as the final result for the location of dipole and its dipole moment. The detailed information of the result is presented in Table 2. The total elapsed time from the beginning of intracloud discharge process to the time at which the field change was measured is given in the second column of Table 2 . The dipole moment neutralized by a-b part for flash 12 was $2.98 \mathrm{C} \mathrm{km}$ with an altitude of $2.6 \mathrm{~km}$. The dipole moment neutralized by a-c part was $8.41 \mathrm{C} \mathrm{km}$ with an altitude of $2.27 \mathrm{~km}$, while those for a-d part were $12.09 \mathrm{C} \mathrm{km}$ and $2.31 \mathrm{~km}$, respectively. The total dipole moment neutralized by intracloud discharge process $(\mathrm{a}-\mathrm{f})$ was $13.4 \mathrm{C} \mathrm{km}$ with a center altitude of $2.0 \mathrm{~km}$. The position of point dipole of
Table 2. Characteristics of preliminary breakdown process

\begin{tabular}{llllllll}
\hline $\begin{array}{l}\text { Interval } \\
\text { number }\end{array}$ & $\begin{array}{l}\text { Time } \\
(\mathrm{ms})\end{array}$ & $\theta$ & $x(\mathrm{~km})$ & $y(\mathrm{~km})$ & $z(\mathrm{~km})$ & $p(\mathrm{C} \mathrm{km})$ & \multicolumn{1}{l}{$\varphi$} \\
\hline $\begin{array}{l}\text { Flash 12 } \\
\text { a-b }\end{array}$ & 74.75 & 30.0 & $-19.0 \pm 0.3$ & $8.3 \pm 0.4$ & $2.60 \pm 0.03$ & $2.98 \pm 0.07$ & $262.5 \pm 2.1$ \\
a-c & 117.76 & 30.0 & $-17.9 \pm 0.3$ & $7.2 \pm 0.4$ & $2.27 \pm 0.03$ & $8.41 \pm 0.23$ & $246.6 \pm 2.1$ \\
a-d & 162.82 & 30.0 & $-18.7 \pm 0.2$ & $6.7 \pm 0.5$ & $2.31 \pm 0.04$ & $12.09 \pm 0.3$ & $241.9 \pm 2.3$ \\
a-f & 195.58 & 30.0 & $-16.2 \pm 0.6$ & $6.4 \pm 0.8$ & $2.00 \pm 0.08$ & $13.4 \pm 1.0$ & $242.3 \pm 5.2$ \\
Flash 13 & & & & & & & \\
a-b & 79.87 & 20.0 & $-21.4 \pm 0.9$ & $9.6 \pm 1.9$ & $3.10 \pm 0.13$ & $6.4 \pm 0.5$ & $259.5 \pm 6.9$ \\
a-c & 141.31 & 20.0 & $-24.3 \pm 0.9$ & $9.5 \pm 2.6$ & $3.4 \pm 0.19$ & $12.9 \pm 1.0$ & $249.8 \pm 7.4$ \\
a-d & 179.2 & 20.0 & $-20.4 \pm 0.8$ & $8.2 \pm 1.7$ & $2.70 \pm 0.13$ & $20.7 \pm 1.6$ & $253.3 \pm 7.4$ \\
a-f & 208.9 & 20.0 & $-21.0 \pm 0.8$ & $8.3 \pm 1.8$ & $2.71 \pm 0.13$ & $29.8 \pm 2.3$ & $252.3 \pm 6.9$ \\
\hline
\end{tabular}



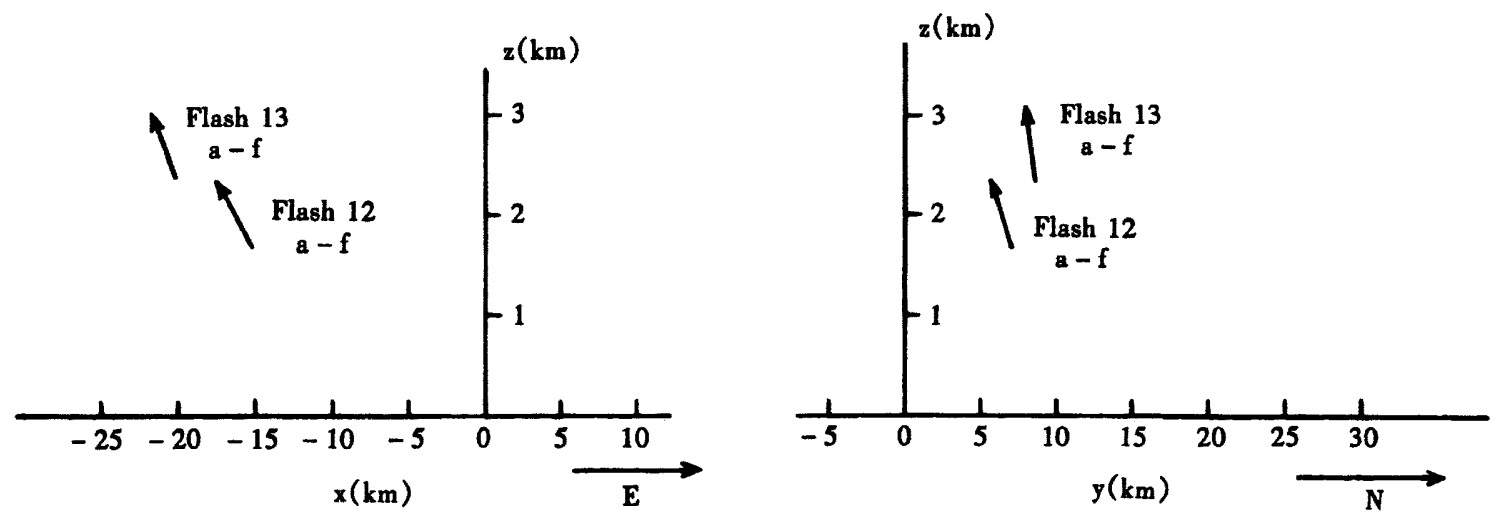

Fig. 7. The projected position in $x-z$ and $y-z$ panel for intracloud discharge process just before first return stroke of flash 12 and flash 13

whole intracloud discharge process (a-f part), projected in $x-z$ and $y-z$ panel, is illustrated in Fig. 7.

The intracloud discharge process just before R1 for flash 13 started with a-b part, whose dipole moment was $6.4 \mathrm{C} \mathrm{km}$, and the corresponding altitude was $3.1 \mathrm{~km}$; the neutralized dipole moment for a-c was $12.9 \mathrm{C} \mathrm{km}$ with an altitude of $3.4 \mathrm{~km}$; the center location of the dipole moment neutralized by a-d was $2.7 \mathrm{~km}$ with the dipole moment of $20.7 \mathrm{C} \mathrm{km}$. The discharge altitude during the whole intracloud discharge process, $a-f$, had hardly changed, and the dipole moment increased to $29.8 \mathrm{C} \mathrm{km}$. Its position projected in $x-z$ and $y-z$ panel also is illustrated in Fig. 7.

According to these results, it is shown that the central location of different phases of intracloud discharge process did not change greatly, so the channel should be established before point $b$. Then the discharge was stable and the discharge channel would not be changed greatly. A further study on the progression of initial streamer before point $\mathrm{b}$ would be of great significance when sufficient data are available.

The data listed in Table 2 were selected from nine groups of results which were calculated by using different elevations increasing from $10^{\circ}$ to $90^{\circ}$ with an increment of $10^{\circ}$. Actually the results were very close for both flashes when $\theta=10^{\circ}, 20^{\circ}, 30^{\circ}$ and $40^{\circ}$ respectively, which indicated that intracloud discharge process just before R1 developed nearly vertically.

\section{Height of the lightning charge}

From our analysis, it is clearly shown that the charge centers for the individual negative ground strokes were located between 3 to $6 \mathrm{~km}$ above the ground, while that for positive ground stroke was at about $2 \mathrm{~km}$ above the ground. These two charge regions were the main sources contributing to cloud-to-ground discharge. Although flash 13 was the only positive flash to the ground we analyzed, the location of intracloud discharge process just before R1 supported this result. In the 1980s, we used the field changes as the storm approached and receded from the field mill stations to infer that the large positive charge region was located at the base of the thundercloud (Wang et al., 1987; Liu et al., 1987).
Although our data covered only one thunderstorm and four ground flashes, these new results and the field mill data of the previous years are consistent.

In contrast, Brook et al. (1982) found that the positive ground flashes initiates in upper positive charge region in the winter thunderstorms of Japan. The occurrence of positive ground flashes is a consequence of the wind shear. The shear provides a horizontal displacement between the charge regions that helps to ensure that an initiating positive streamer will continue down to ground rather than into the negative charge region that would normally be located directly below it. They suggested that positive ground flashes should appear at a threshold shear value in the cloud layer of about $1.5 \mathrm{~m} / \mathrm{s} / \mathrm{km}$. The variations in charge sources corresponding to positive ground flash between Japan and Chinese Inland Plateau may result from the differences in charge structures of thunderstorm which depend on the season, meteorological conditions and other factors.

\section{Relation to storm structure}

As described earlier, a 5-cm wavelength radar was operated during the observations, and atmospheric sounding data were obtained from 0700 (Beijing Time) measurements. The positive and negative charge centers for individual ground strokes were located at $2 \mathrm{~km}$ and 3-6 $\mathrm{km}$ above the ground, respectively. At these elevations the environmental clear air temperature at the time of sounding ranged between -2 and $-15^{\circ} \mathrm{C}$ for negative charges, and $+5{ }^{\circ} \mathrm{C}$ for positive charges. The cloud base was close to the ground. All negative charges are confined to the cold part of the cloud (below $0{ }^{\circ} \mathrm{C}$ ). This result is consistent with earlier studies in New Mexico (Krehbiel et al., 1979) and in Florida (Jacobson and Krider, 1976). They found the charges neutralized by negative ground flashes were located in the temperature zone between -5 and $-25^{\circ} \mathrm{C}$.

Figure 8 shows the RHI radar echo obtained closest to four flashes, respectively. The clear air temperature at 0700 is also shown to the right of each radar echo as reference. Charge sources for the individual ground strokes of these flashes coincided reasonably well with 

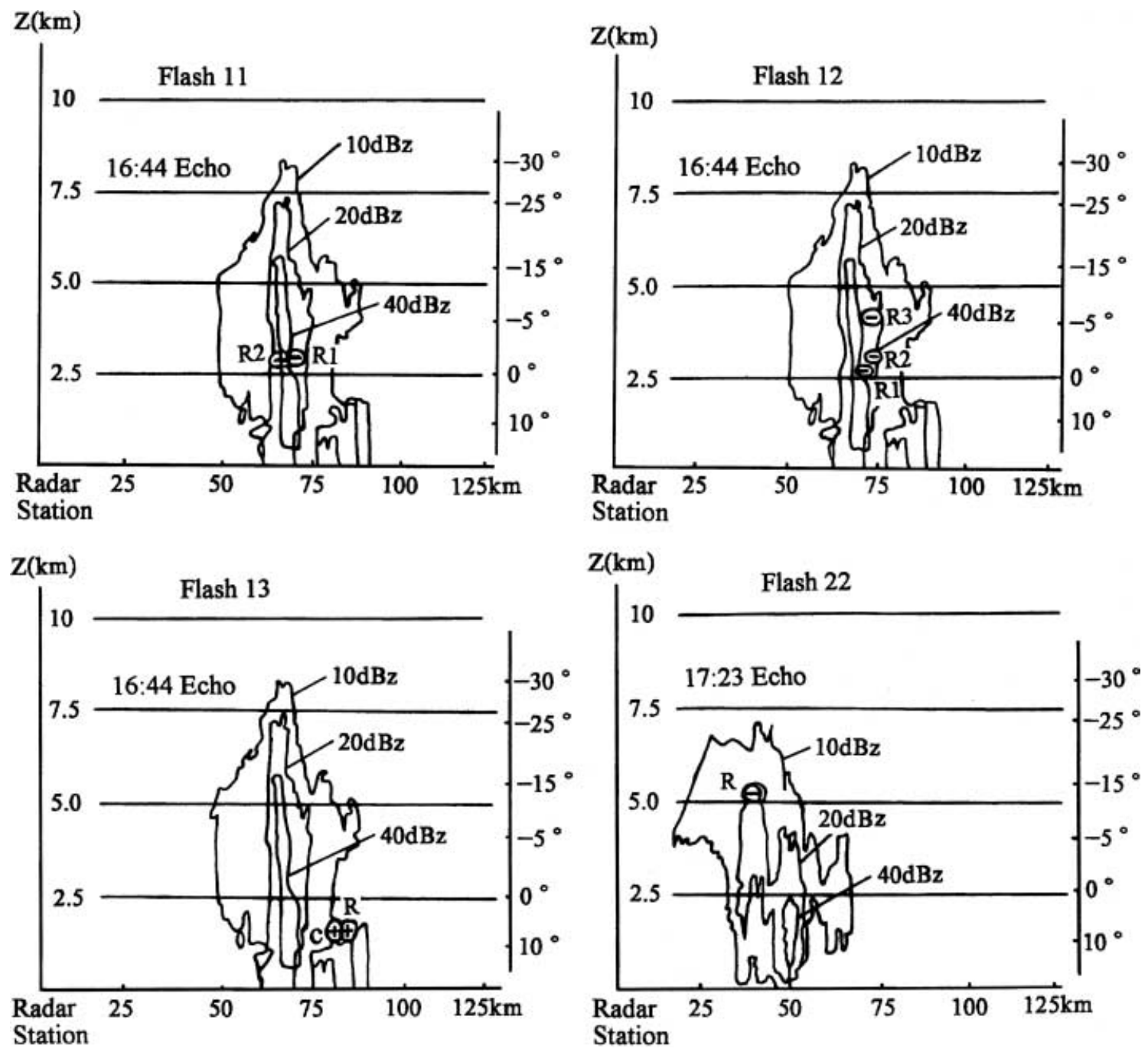

Fig. 8. The RHI radar echo obtained closest to four particular flashes, numbered $11-13$ and 22 . The clear air temperature at 0700 is also shown on the right of each radar echo

the radar echoes and accordingly were superimposed on them. We contoured the radar data at $10 \mathrm{dBZ}, 20 \mathrm{dBZ}$ and $40 \mathrm{dBZ}$ levels. The good agreement suggests that the model we used here is reasonable. All negative flashes were initiated in the region greater than $20 \mathrm{dBZ}$ or near the edge of the region with intense echo greater than 40 $\mathrm{dBZ}$ except the first return stroke in flash 12 , while the location of positive flash was in the echo region with 10 dBZ which was $84 \mathrm{~km}$ away from the radar. These results agree with previous results obtained by comparing the data from radar echo with DF data (Ge et al., 1992). They found that negative ground flashes occurred often near, but not in, the strong echo center, and there was a positive correlation between the rate of the negative ground flashes and radar area of the intensity greater than $30 \mathrm{dBZ}$, while positive ground flashes usually occurred in weak echo region and the flash rate decreased with the increase of storm intensity.

The horizontal locations of intracloud discharge process just before R1 indicate that the centers of the dipole moment were at about $74 \mathrm{~km}$ away from the radar station. Referring to the radar echo at 16:44 shown in Fig. 8, we can see that the dipole moment centers fall between the positive and negative charge center. These along with the ground discharge of flash 13 confirm again the existence of the lower positive charge region and the reliability of these results.

\section{Summary and discussion}

In this study we have presented the results of multistation electric field measurements for four cloud-toground flashes in one thunderstorm which occurred on August 12, 1996, in Zhongchuan area, on the edge of Qinghai-Xizang Plateau of China. The basic conclusions are summarized as follows:

1. One positive cloud-to-ground flash (flash 13) consisted of only one return stroke which was followed by a long continuing current event. Negative ground discharges usually consisted of several return strokes. The magnitude of charge flowing to the ground for three negative ground flashes was about $-10 \mathrm{C}$, while a charge of $68.31 \mathrm{C}$ was transferred for the one 
positive flash. The sources of charge for successive negative strokes of the flashes to the ground developed over large horizontal distance (up to $5.4 \mathrm{~km}$ ) within the cloud at almost a constant elevation.

2. The sources of charge for three negative ground flashes were confined between 2.74 to $5.41 \mathrm{~km}$ above the ground $(2 \mathrm{~km}$ asl), while that for one positive ground stroke and one continuing current process occurred at about $2.0 \mathrm{~km}$ above the ground.

3. In the Chinese Inland Plateau, cloud-to-ground discharges were preceded by a long-duration of intracloud discharges which lasted $120 \mathrm{~ms}$ to $300 \mathrm{~ms}$ for $85 \%$ of cloud-to-ground flashes, with a mean duration of $189.7 \mathrm{~ms}$. For the two analyzed cases, the central altitudes of the discharge, determined by using the point-dipole model, were about 2.3 to $3.4 \mathrm{~km}$, and the dipole moments were between 13 to $30 \mathrm{C} \mathrm{km}$ with a charge structure of negative in the upper part and positive in the lower part.

4. The comparison with radar echo shows that the negative discharges initiated in the region greater than $20 \mathrm{dBZ}$ or near the edge of the region with intense echoes greater than $40 \mathrm{dBZ}$, while positive discharges initiated in a relatively weak echo region.

Although a discrete dipole model would have been a better method to analyze sources of charge neutralized by intracloud lightning discharges, here, because of the limited station number, we used a simpler model, i.e., the point dipole charge model. This model may cause significant error when an intracloud discharge process is analyzed, especially if the charge neutralized by the lightning discharge was distributed in non-uniform or non-spherical distribution. Furthermore the thunderstorm was far from the network center, so the results may not be necessarily precise. Even if there were enough stations, one could not resolve the two charge centers in the cloud using the discrete dipole model due to the large distance of the flash from the measurement stations. On the other hand, the results here are in good agreement with radar data and have a clear physical meaning, which indicate that the results are of a certain reliability.

These results are from only four ground flashes in one thunderstorm, and may not represent all lightning discharges in Chinese Inland Plateau. Perhaps these few flashes are typical of a specific type of storm, weather pattern, season, and so on. Because the locations of positive charge sources are consistent with that of field mill data in previous results (Wang et al., 1987; Liu et al., 1989), we suppose that there is a horizontally extensive positive charge region of large magnitude and wide dimension at base of the thunderstorm. The questions as to why a large number of positive charges exist at base of the cloud and why lower positive charges seem to be more effective in discharge processes in
Chinese Inland Plateau remain unanswered. It could be some unknown electrification mechanisms exist in this area.

Acknowledgements. We thank Professor P.R. Krehbiel and an anonymous referee for their helpful comments. The experiment was supported by National Natural Science Foundation of China (Grant 49975003), Chinese Academy of Sciences (Grant KZ951$\left.\mathrm{B}_{1}-405\right)$ and the cooperation project between China and Japan.

Topical Editor D. Murtagh thanks P.R. Krehbiel and C.G. Price for their help in evaluating this paper.

\section{References}

Barnard, V., The approximate mean height of the thundercloud charges taking part in a flash to the ground, J. Geophys. Res., 56, 33-35, 1951.

Brook, M., M. Nakano, and P. Krehbiel, The electrical structure of the Hokuriku winter thunderstorm, J. Geophys. Res., 87, 12071215, 1982.

Ge Z., M. Yan, C. Guo, and G. Zhang, Analysis of cloud-to-ground lightning characteristics in mesoscale storm in Beijing area, Acta Meteorol. Sinica, 2, 491-500, 1992.

Jacobson, E. A., and E. P. Krider, Electrostatics field changes produced by Florida lightning, J. Atmos. Sci., 33, 103-117, 1976.

Koshak, W. J., and E. P. Krider, Analysis of lightning field changes during active Florida thunderstorms, J. Geophys. Res., 94, 1165-1186, 1989.

Krehbiel, P. R., M. Brook, and R. A. McCrog, An analysis of the charge structure of lightning discharge to the ground, J. Geophys. Res., 84, 2432-2456, 1979.

Krider, E. P., Electric field changes and cloud electric structure, J. Geophys. Res., 94, 13 145-13 149, 1989.

Liu, X., and P. R. Krehbiel, The initial streamer of intracloud lightning flashes, J. Geophys. Res., 90, 6211-6218, 1985.

Liu, X., C. Guo, C. Wang, and M. Yan, The surface electrostatic field-change produced by lightning flashes and the positive charge layer of the thunderstorm (in Chinese), ACTA Meteorol. Sinica, 45, 500-504, 1987.

Liu, X., Z. Ye, X. Shao, C. Wang, M. Yan, and C. Guo, Intracloud lightning discharge in the lower part of thundercloud, Acta Meteorol. Sinica, 3, 212-219, 1989.

Maier, L. M., and E. F. Krider, The charges that deposited by cloud-to-ground lightning in Florida, J. Geophys. Res., 91, 13 275-13 289, 1986.

Murphy, M. J., E. P. Krider, and M. W. Maier, Lightning charge analysis in small CaPE storms, J. Geophys. Res., 101, 29 615$29626,1996$.

Ogawa, T., and M. Brook, Charge distribution in thunderstorm cloud, Q. J. Roy. Meteorol. Soc., 95, 513-525, 1969.

Reynolds, S. E., and H. W. Neill, The distribution and discharge of thunderstorm charge-centers, J. Meteorol., 12, 1-12, 1955.

Ushio, T., Z.-I. Kawasaki, and K. Matuura, Electric fields of initial breakdown in Lightning, Proc. 10th International Conference on Atmospheric Electricity, 588-591, 1996.

Wang, C., Q. Chen, X. Liu, C. Guo, and Z. Ge, The electric field produced by the lower positive charge center of thunderstorm (in Chinese), Plateau Meteorol., 6, 65-74, 1987.

Workman, E. J., and R. E. Holler, A preliminary investigation of the electrical structure of thunderstorms, Are. Tech. Note, 850, 1942. 